\title{
BENEFÍCIOS TRIBUTÁRIOS VALEM A PENA? UM ESTUDO DE FORMULAÇÃO DE POLÍTICAS PÚBLICAS
}

\author{
Wagner Pralon Mancuso
}

\author{
Davi Cordeiro Moreira
}

\begin{abstract}
RESUMO
O objeto do artigo são os dispositivos legais aprovados entre 05/10/1988 (promulgação da atual Constituição) e 01/ 01/2009 (último dia da primeira metade do segundo mandato presidencial de Luiz Inácio Lula da Silva), que concederam benefícios tributários ao empresariado, referentes a três tributos que financiam a ação social da União: PIS, COFINS e CSLL. O objetivo é analisar se a formulação desses dispositivos foi marcada pela preocupação com medidas para assegurar a transparência, a eficiência, a eficácia e a efetividade dos benefícios - valores fundamentais para boas políticas públicas. Para este fim foram analisadas a origem, a espécie e a exposição de motivos das proposições legislativas que instituíram beneficios tributários para o empresariado, bem como o conteúdo dos dispositivos legais efetivamente aprovados. A principal conclusão do trabalho é que a preocupação com os valores da transparência, eficiência, eficácia e efetividade parece ter sido escassa na formulação dos dispositivos legais. Essa constatação é preocupante, pois é crescente o número de leis que instituem benefícios tributários, e é gigantesco o volume de renúncias tributárias realizadas. A concessão de beneficios tributários ao empresariado caracteriza-se como uma política distributiva, nos termos de Lowi (1964). Políticas distributivas, com beneficios concentrados e custos difusos, tendem a ser precedidas por intenso lobby favorável de seus potenciais beneficiários, e tendem a provocar mobilização muito menor - se houver alguma - do restante da sociedade, em sentido oposto. Este viés favorável a interesses especiais pode colocar o interesse público em risco. Esse risco, todavia, não é inevitável, pois benefícios tributários podem colaborar para a produção de resultados socialmente positivos, tal como ocorreu quando foram incluidos no rol de medidas exitosamente implementadas pelo governo brasileiro para mitigar os efeitos internos da crise internacional de 2008. O desafio, então, é enfrentar os riscos colocados pela concessão de beneficios tributários ao empresariado com a arquitetura institucional adequada.
\end{abstract}

PALAVRAS-CHAVE: benefícios tributários; empresariado; política distributiva. formulação de políticas públicas.

\section{INTRODUÇÃO: BENEFÍCIOS TRIBUTÁRIOS PARA O EMPRESARIADO: UM ASSUNTO IMPORTANTE $^{1}$}

Este artigo desenvolve e aprofunda aspectos centrais de análise iniciada em recente trabalho anterior (MANCUSO, GONÇALVES \& MENCARINI, 2010, p. 213-237). Em síntese, os autores argumentam naquele texto que a concessão de benefícios tributários ao empresariado ( $i$ ) é frequente no Brasil; (ii) ocasiona uma gigantesca renúncia de receitas, que poderiam ser revertidas em serviços públicos e cujo montante é sistematicamente subestimado; (iii) coloca o risco de rent-seeking por parte de interesses estreitos e privilegiados $^{2}$ e $(i v)$ apresenta problemas relevantes

\footnotetext{
1 Agradecemos aos pareceristas da Revista de Sociologia e Política pela análise e sugestões feitas a este trabalho.

2 "Rent seeking" (TULLOCK, 1989; 1993) é o comportamento do ator social que utiliza recursos políticos para tentar manipular o poder público e, com isso, obter privilégios especiais. $\mathrm{O}$ prejuízo para a sociedade como um todo, resultante desses pri-
}

nas fases de formulação, implementação e avaliação problemas cuja solução é imprescindível para que o eventual potencial positivo dos benefícios tributários possa emergir.

Além de conter essa parte de "diagnóstico", o trabalho anterior contém também uma parte de "tratamento", pois apresenta uma lista de medidas que poderiam ser adotadas para aprimorar a formulação, a implementação e a avaliação dos diplomas legais que concedem benefícios tributários a empresas no Brasil ${ }^{3}$.

vilégios especiais, ultrapassa o benefício apropriado pelo ator favorecido. A literatura sobre benefícios tributários (GRAETZ, 2007; DEVER JR., 2008) aponta a possibilidade de quid pro quo entre políticos e empresários beneficiados - por meio, por exemplo, de financiamento de campanhas eleitorais.

3 Tanto o trabalho anterior quanto o atual baseiam-se no modelo do "ciclo das políticas públicas" (RIPLEY, 1995), segundo o qual o processo das políticas públicas pode ser descrito como um ciclo dividido em estágios como definição da agenda, formulação, implementação e avaliação. Uma das vantagens desse modelo é que ele favorece a investigação pormenorizada dos 
No que tange ao estágio da formulação, as medidas sugeridas são as seguintes: $(i)$ que as proposições legislativas que instituem benefícios tributários sejam precedidas de discussão com a sociedade em consultas ou audiências públicas "abertas e amplamente divulgadas", para evitar a tomada de decisão "em ambientes de pouca visibilidade, afastados do escrutínio público, respondendo apenas à pressão de setores que têm lobbies poderosos, em vez de atenderem a critérios claros, bem definidos, publicamente defensáveis e de validade geral" e (ii) que as proposições legislativas sejam baseadas em evidências sólidas de eficiência, eficácia e efetividade ${ }^{4}$. Para esse fim, deveria haver (a) melhora das estimativas de renúncia; (b) definição realista e precisa dos resultados que se deseja obter com a renúncia tributária (não apenas em termos de ganhos para os "insiders" empresários, fornecedores, empregados e consumidores -, mas também em termos de externalidades positivas para o restante da sociedade) e (c) apresentação de evidências convincentes de que a renúncia tributária é um meio adequado para alcançar os resultados desejados, e de que tais resultados compensam os custos projetados.

Quanto ao estágio da implementação, duas sugestões são propostas: $(i)$ a constante consolidação da legislação sobre benefícios tributários, para facilitar o acompanhamento da trajetória da política pelos próprios órgãos do poder público, pelos empresários e pelos demais interessados na matéria (mídia, academia, sociedade civil organizada e cidadãos em geral) e (ii) o cálculo da renúncia efetiva, com indicação dos beneficiários. Esse cálculo (a) favoreceria a transparência; (b) facilitaria a cobrança dos beneficiários a efetuar eventuais contrapartidas; (c) contribuiria para o aprimoramento de novas estimativas de renúncia futura, a serem feitas na formulação de novos dispositivos e (d) proporcionaria uma informação valiosa a ser considerada no estágio de avaliação dos dispositivos existentes.

No que diz respeito ao estágio da avaliação, o trabalho propõe a construção de indicadores que meçam o efeito das renúncias tributárias sobre resultados

problemas específicos de cada estágio da política pública em análise.

4 "Eficiência" refere-se à relação benefício-custo da política. A política mais eficiente apresenta a melhor relação benefício-custo. "Eficácia" refere-se à capacidade da política de produzir os resultados desejados. "Efetividade" refere-se à produção de fato dos resultados desejados, quando a política é realmente adotada. Consultar Secchi (2010, p. 49-53) para aprofundamento nesses conceitos. definidos na fase da formulação e buscados na fase da implementação. Tais indicadores seriam úteis para analisar a política de benefícios tributários sob a óptica da eficiência, da eficácia e da efetividade; bem como para instruir as decisões sobre o futuro dessa política - ou seja, para decidir, caso a caso, se os benefícios existentes deveriam ser ampliados, mantidos, reduzidos ou extintos.

Nosso objetivo específico neste trabalho é verificar se as leis que instituíram os benefícios tributários continham as medidas apontadas no trabalho anterior (MANCUSO, GONÇALVES \& MENCARINI, 2010) como importantes para assegurar a transparência, a efíciência, a efícácia e a efetividade dos benefícios. Portanto, o foco deste trabalho está posto exclusivamente no estágio da formulação dos dispositivos legais. Trabalhos posteriores focalizarão os estágios de implementação e avaliação.

O universo de análise é formado por 52 dispositivos legais aprovados no período de pouco mais de 20 anos, situado entre 5 de outubro de 1988 (data da promulgação da atual constituição do Brasil) e $1^{\circ}$ de janeiro de 2009 (último dia da primeira metade do segundo mandato presidencial de Luiz Inácio Lula da Silva). Desse modo, o trabalho focaliza todos os dispositivos legais do período mencionado que concederam ao empresariado benefícios referentes a três tributos que financiam a ação social da União: a Contribuição para o Programa de Integração Social (PIS), a Contribuição Social sobre o Lucro Líquido (CSLL) e a Contribuição para o Financiamento da Seguridade Social (Cofins). A contribuição para o PIS financia o programa de seguro-desemprego, o abono anual de um salário-mínimo para empregados que recebem até dois salários-mínimos mensais e programas de desenvolvimento econômico financiados pelo Banco Nacional de Desenvolvimento Econômico e Social (BNDES) ${ }^{5}$. Já a CSLL e a Cofins destinam-se ao financiamento da seguridade social (saúde, previdência e assistência social) ${ }^{6}$.

O Quadro 1 identifica esses 52 dispositivos legais, dividindo-os simultaneamente por tipos e pelo governo que os adotou 7 . O tipo mais adotado de dispositivo

\footnotetext{
5 Conforme o artigo 239 da Constituição de 1988. A contribuição para o PIS foi instituída pela Lei Complementar n. 7, de 7 de setembro de 1970.

6 A CSLL foi instituída pela Lei n. 7 689, de 15 de dezembro de 1988. A Cofins foi instituída pela Lei Complementar n.. 70, de 30 de dezembro de 1991.

7 O quadro atualiza as informações apresentadas em Mancuso, Gonçalves e Mencarini (2010, p. 222-225).
} 
(32 dispositivos, ou 61,5\% do total) é o que favorece empresas de segmentos específicos dos setores primário, secundário ou terciário (e, eventualmente, seus fornecedores e clientes). Esse tipo de dispositivo passa a ser utilizado com mais freqüência durante o primeiro governo de Fernando Henrique Cardoso, mas a grande explosão de uso dessa modalidade de benefícios ocorre durante o segundo governo Cardoso e mantém-se sob os dois governos de Lula.

O segundo tipo mais freqüente de dispositivo é o que beneficia empresas exportadoras. Eles são adotados com o propósito de promover a competitividade externa da empresa brasileira, estimular a entrada de divisas, beneficiar a balança comercial do país etc.

O terceiro tipo de dispositivo institui renúncia tributária em favor das sociedades cooperativas. Benefícios tributários favoráveis às cooperativas remontam ao governo Collor, mas ganharam força na segunda metade do segundo governo Cardoso e - sobretudo na primeira metade do primeiro governo Lula.

O quarto tipo de dispositivo beneficia microempresas e empresas de pequeno porte. Leis que instituem benefícios tributários para esse segmento foram aprovadas sob o governo Collor, sob os dois governos de Fernando Henrique Cardoso e, em maior número, sob o primeiro governo Lula.
O primeiro governo Lula também se destacou como o período de maior adoção do quinto tipo de dispositivo, que favorece empresas localizadas em determinadas regiões do país (sobretudo as da Zona Franca de Manaus).

O sexto tipo de dispositivo contempla empresas que aderem a programas do governo. Por exemplo, sob o primeiro governo Cardoso, um dispositivo reduziu a base de cálculo da CSLL para os portadores de títulos emitidos para uso no programa nacional de privatização. Sob o primeiro governo Lula, as instituições de ensino superior que aderiram ao "Programa Universidade para Todos" (Prouni) ficaram isentas das três contribuições sociais.

O sétimo tipo de dispositivo tem como alvo as empresas que oferecem benefícios aos empregados. Medidas que reduzem a base de cálculo da CSLL foram adotadas no primeiro governo Cardoso para beneficiar empresas que contribuem para planos de previdência privada de seus empregados. Sob o mesmo governo, a Lei n. 9 249/95 reduziu a base de cálculo da CSLL para empresas que fornecem alimentação aos seus empregados, bem como para empresas que fazem doações a entidades civis, sem fins lucrativos, que prestem serviços gratuitos em benefício de seus empregados e dependentes.

QUADRO 1 - DISPOSITIVOS LEGAIS QUE CONCEDERAM BENEFÍCIOS TRIBUTÁRIOS AO EMPRESARIADO, RELATIVOS À CONTRIBUUIÇÃO PARA O PIS, À COFINS E À CSLL, POR TIPO E GOVERNO (1988-2008)

\begin{tabular}{|c|c|c|c|c|c|c|c|}
\hline & \begin{tabular}{c|} 
SARNEY \\
$(5$. out.1988- \\
15.mar.1990)
\end{tabular} & $\begin{array}{c}\text { COLLOR } \\
\text { (15.mar.1990- } \\
\text { 2.out.1992) }\end{array}$ & $\begin{array}{l}\text { FRANCO } \\
\text { (2.out.1992- } \\
\text { 1.jan.1995) }\end{array}$ & $\begin{array}{l}\text { CARDOSO I } \\
\text { (1.jan.1995- } \\
\text { 1.jan.1999) }\end{array}$ & $\begin{array}{l}\text { CARDOSO II } \\
\text { (1.jan.1999- } \\
\text { 1.jan.2003) }\end{array}$ & $\begin{array}{c}\text { LULA I } \\
\text { (1.jan.2003- } \\
\text { 1.jan.2007) }\end{array}$ & $\begin{array}{c}\text { LULA II } \\
\text { (1.jan.2007- } \\
\text { 1.jan.2009) }\end{array}$ \\
\hline $\begin{array}{l}\text { Empresas de } \\
\text { segmentos } \\
\text { específicos }\end{array}$ & & $\begin{array}{c}\text { Lei n. } 8 \text { 398, de } \\
\text { 7.jan. } 1992\end{array}$ & & $\begin{array}{c}\text { Lei } \\
\text { Complementar } \\
\text { n. } 85, \text { de } \\
\text { 15.fev.1996 } \\
\text { Lei n. } 9493 \text {, } \\
\text { de 10.set.1997 } \\
\text { Lei n. } 9701 \text {, } \\
\text { de } \\
\text { 17.nov.1998 } \\
\text { Lei n. } 9715 \text {, } \\
\text { de } \\
\text { 25.nov.1998 } \\
\text { Lei n. } 9718, \\
\text { de } 27 . \text { nov.98 }\end{array}$ & 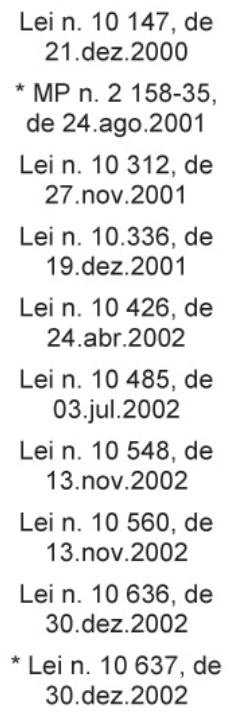 & $\begin{array}{c}\text { Lei n. } 10684 \text {, de } \\
30 . \text { maio.2003 } \\
\text { Lei n. } 10833 \text {, de } \\
\text { 29.dez.2003 } \\
\text { Lei n. } 10865 \text {, de } \\
\text { 30.abr.2004 } \\
\text { Lei n. } 10925 \text {, de } \\
\text { 23.jul.2004 } \\
\text { Lei n. } 10996 \text {, de } \\
\text { 15.dez.2004 } \\
\text { Lei n. } 11033 \text {, de } \\
\text { 21.dez.2004 Lei n. } \\
\text { 11 } 051, \text { de } \\
\text { 29.dez.2004 } \\
\text { Lei n. } 11116 \text {, de } \\
\text { 18.maio.2005 } \\
\text { Lei n. } 11196 \text {, de } \\
\text { 21.nov.2005 }\end{array}$ & $\begin{array}{l}\text { Lei } n .11484 \text {, de } \\
\text { 31.maio. } 2007 \\
\text { Lei n. } 11488 \text {, de } \\
\text { 15.jun. } 2007 \\
\text { Lei n. } 11529 \text {, de } \\
\text { 22.out. } 2007 \\
\text { Lei n. } 11727 \text {, de } \\
\text { 23.jun.2008 } \\
\text { Lei n. } 11774 \text {, de } \\
\text { 17.set.2008 } \\
\text { Lei n. } 11787 \text {, de } \\
\text { 25.set. } 2008 \\
\text { Lei n. } 11827 \text {, de } \\
\text { 20.nov. } 2008\end{array}$ \\
\hline
\end{tabular}




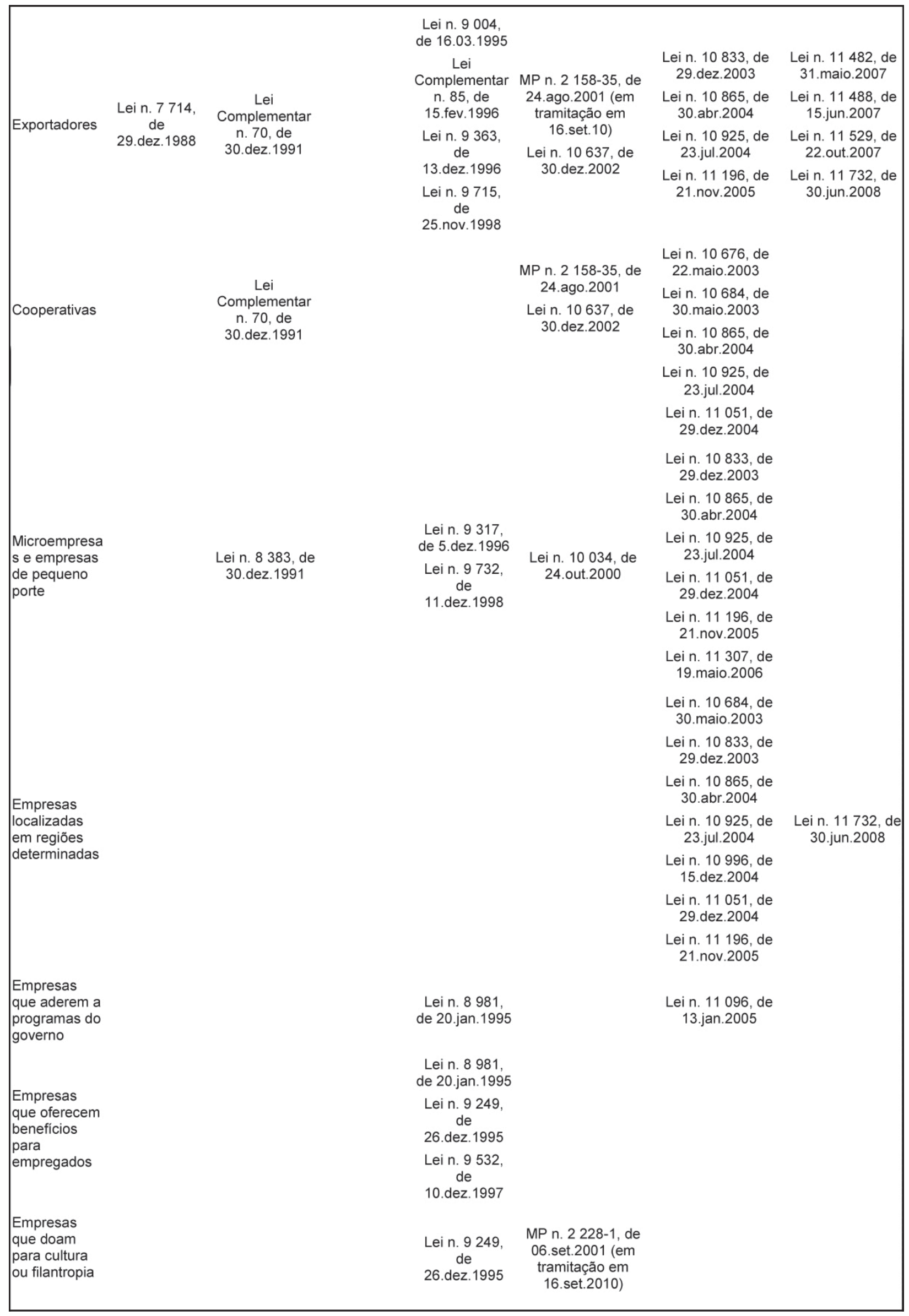




\begin{tabular}{|c|c|c|c|c|c|c|c|}
\hline $\begin{array}{l}\text { Empresas } \\
\text { inadimplentes } \\
\text { ou } \\
\text { adimplentes }\end{array}$ & & & $\begin{array}{c}\text { Lei n. } 8696 \text {, } \\
\text { de } \\
\text { 26.ago.1993 }\end{array}$ & & $\begin{array}{l}\text { Lei n. } 10637 \text {, de } \\
30 . \text { dez.2002 }\end{array}$ & & \\
\hline $\begin{array}{l}\text { Empresas } \\
\text { que investem }\end{array}$ & & & & & $\begin{array}{l}\text { Lei n. } 10637 \text {, de } \\
30 . \text { dez.2002 }\end{array}$ & $\begin{array}{l}\text { Lei n. } 11 \text { 196, de } \\
\text { 21.nov. } 2005\end{array}$ & $\begin{array}{c}\text { Lei } \mathrm{n} .11484 \text {, de } \\
\text { 31.maio.2007 }\end{array}$ \\
\hline \multirow[t]{2}{*}{ em C\&T } & & & & & & & $\begin{array}{c}\text { Lei n. } 11487 \text {, de } \\
\text { 15.jun.2007 }\end{array}$ \\
\hline & & & & & & & $\begin{array}{c}\text { Lei n. } 11774, \mathrm{de} \\
17 . \text { set.2008 }\end{array}$ \\
\hline \multirow{2}{*}{$\begin{array}{l}\text { Empresas } \\
\text { com } \\
\text { participação } \\
\text { do poder } \\
\text { público }\end{array}$} & & & & & & \multirow{2}{*}{$\begin{array}{l}\text { Lei n. } 10865 \text {, de } \\
30 . a b r .2004\end{array}$} & $\begin{array}{c}\text { Lei n. } 11727 \text {, de } \\
\text { 23.jun.2008 }\end{array}$ \\
\hline & & & & & & & $\begin{array}{l}\text { Lei n. } 11828, \mathrm{de} \\
\text { 20.nov.2008 }\end{array}$ \\
\hline TOTAL & 1 & 3 & 1 & 12 & 12 & 12 & 11 \\
\hline
\end{tabular}

FONTE: Elaboração própria, a partir de levantamento na LEX, nos Demonstrativos de Benefícios Tributários (19892008) e no portal da Presidência da República na Internet, seção de legislação (BRASIL, 2013).

O oitavo tipo de dispositivo focaliza empresas que fazem doações financeiras para a área de cultura ou filantropia. Durante o primeiro governo Cardoso, uma lei reduziu a base de cálculo da CSLL para empresas que fazem doações financeiras em apoio à cultura, bem como para empresas que doam a instituições de ensino e pesquisa comunitárias, confessionais e filantrópicas. No segundo governo Cardoso, outro dispositivo reduziu a base de cálculo da CSLL para empresas que adquirirem cotas dos Fundos de Financiamento da Indústria Cinematográfica Nacional.

O nono tipo de dispositivo é dedicado a empresas conforme sua situação de inadimplência ou adimplência com as contribuições sociais. Durante o governo Franco, uma lei destinada às empresas inadimplentes reduziu a multa sobre pagamento atrasado, bem como permitiu o parcelamento de débitos. Ao final do segundo governo Cardoso, a Lei n. 10 637/02 reduziu a multa e os juros devidos por empresas em débito com o PIS, e instituiu bônus de adimplência fiscal para empresas adimplentes com a CSLL.

As empresas que investem em ciência e tecnologia, registro de patentes, e em áreas como normalização técnica, metrologia e avaliação de conformidade também receberam benefícios tributários referentes às contribuições sociais, por meio de leis aprovadas no final do segundo governo Cardoso, no primeiro governo Lula e, sobretudo, no segundo governo Lula.

Por último, sob os dois governos Lula, foram aprovadas leis que instituem benefícios tributários para empresas com participação do poder público.

É gigantesco o montante de renúncias tributárias gerado por esses dispositivos legais. A Tabela 1 mostra, para o período coberto pela pesquisa, uma estimativa da renúncia tributária da União, provocada pelos benefícios referentes à Contribuição para o PIS, à Cofins e à CSLL. 
TABELA 1 - ESTIMATIVA DO MONTANTE DE RENÚNCIA TRIBUTÁRIA DA UNIÃO, POR CAUSA DE BENEFÍCIOS TRIBUTÁRIOS CONCEDIDOS AO EMPRESARIADO, RELATIVOS À CONTRIBUIÇÃO PARAO PIS, À COFINS E À CSLL (1989-2008) - EM R\$

\begin{tabular}{|c|c|c|c|c|c|c|c|c|c|c|c|c|c|c|c|c|c|c|c|c|c|c|}
\hline & 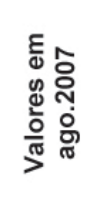 & ' & ' & ' & ' & . & & 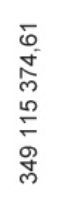 & 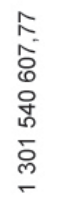 & 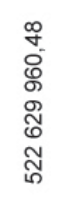 & 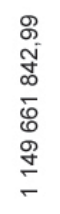 & 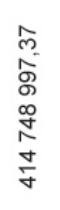 & 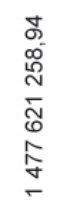 & 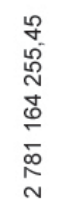 & 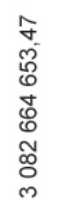 & 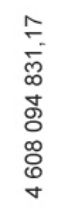 & 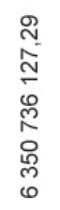 & 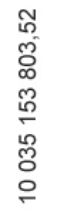 & 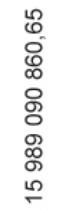 & 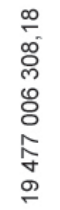 & 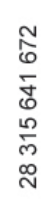 & 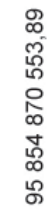 \\
\hline & 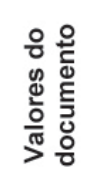 & $\bar{\omega}$ & के & $\bar{\omega}$ & के & $\bar{\omega}$ & $\overline{\text { के }}$ & $\begin{array}{l}\hat{~} \\
\stackrel{+}{\sigma} \\
\stackrel{\infty}{\infty} \\
\stackrel{\infty}{=}\end{array}$ & $\begin{array}{l}\text { 吕 } \\
\stackrel{0}{0} \\
\stackrel{0}{\circ} \\
\stackrel{0}{\circ}\end{array}$ & $\begin{array}{l}8 \\
8 \\
0 \\
\circ \\
0 \\
0\end{array}$ & $\begin{array}{l}\stackrel{0}{0} \\
\stackrel{N}{N} \\
\stackrel{0}{0} \\
0 \\
0\end{array}$ & 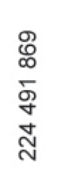 & 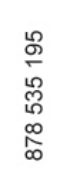 & 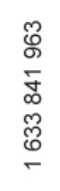 & 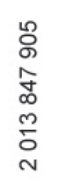 & 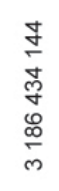 & 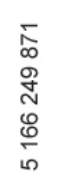 & 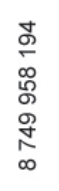 & 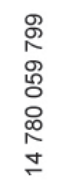 & 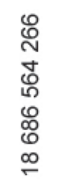 & 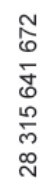 & \\
\hline \multirow{2}{*}{$\overline{\bar{g}}$} & 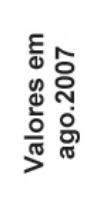 & ' & ' & , & ' & ' & & ' & ' & 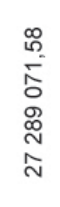 & 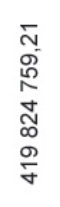 & 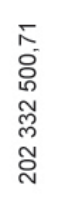 & $\begin{array}{l}m \\
m \\
\infty \\
\infty \\
\infty \\
o \\
0 \\
0 \\
m\end{array}$ & 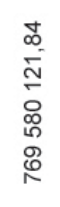 & 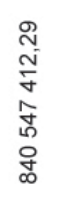 & 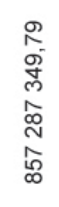 & 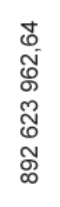 & 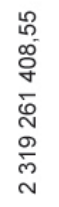 & 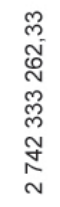 & 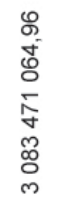 & 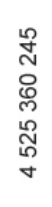 & $\begin{array}{l}\text { N } \\
\text { N } \\
0 \\
0 \\
0 \\
0 \\
0 \\
0 \\
0\end{array}$ \\
\hline & 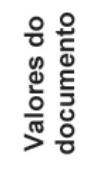 & $\bar{\omega}$ & के & के & के & $\bar{\omega}$ & $\bar{\omega}$ & $\bar{\omega}$ & $\bar{\omega}$ & $\begin{array}{l}8 \\
\circ \\
0 \\
0 \\
0 \\
\end{array}$ & 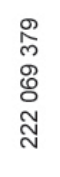 & 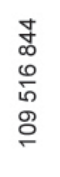 & $\begin{array}{l}\stackrel{\sim}{\infty} \\
\underset{N}{\sim} \\
\underset{N}{+}\end{array}$ & 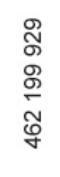 & $\begin{array}{l}8 \\
\stackrel{0}{0} \\
\frac{7}{0} \\
\stackrel{0}{0}\end{array}$ & 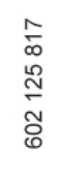 & 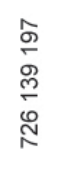 & $\begin{array}{l}\underset{\Sigma}{D} \\
\underset{\sim}{N} \\
\underset{N}{N}\end{array}$ & 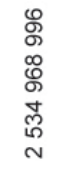 & 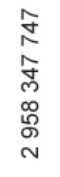 & 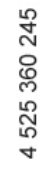 & \\
\hline \multirow{2}{*}{ 总 } & 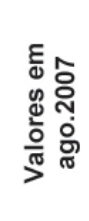 & ' & ' & ' & ' & ' & ' & $\begin{array}{l}\bar{b} \\
o \\
\infty \\
0 \\
0 \\
0 \\
F\end{array}$ & 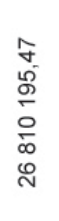 & $\overline{\text { के }}$ & 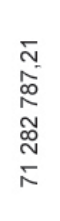 & $\overline{\bar{\omega}}$ & 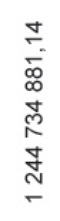 & 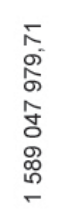 & 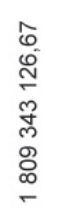 & 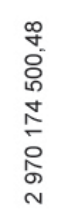 & 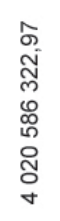 & 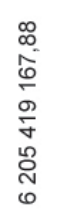 & 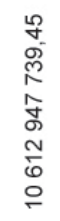 & 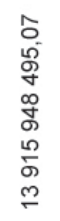 & 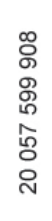 & 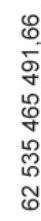 \\
\hline & 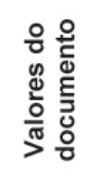 & के & $\bar{\omega}$ & के & के & $\bar{\omega}$ & $\overline{\text { के }}$ & 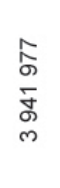 & 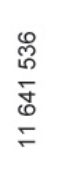 & के & $\begin{array}{l}\text { No } \\
0 \\
0 \\
0 \\
\hat{m}\end{array}$ & $\bar{\omega}$ & $\begin{array}{l}8 \\
0 \\
0 \\
0 \\
0 \\
0 \\
1\end{array}$ & 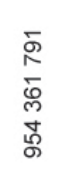 & 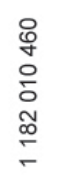 & 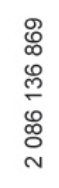 & 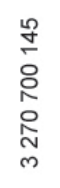 & 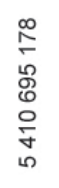 & 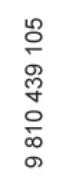 & 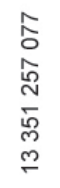 & 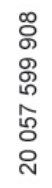 & \\
\hline \multirow[t]{2}{*}{$\underline{\Omega}$} & 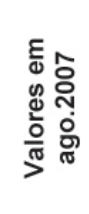 & ' & ' & ' & ' & ' & , & 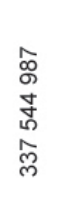 & 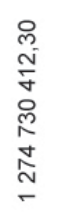 & 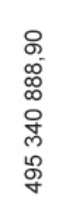 & 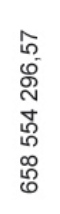 & 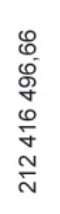 & 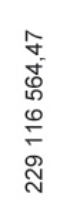 & 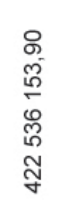 & 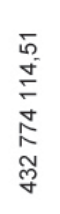 & 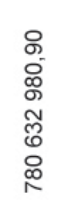 & 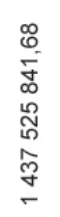 & 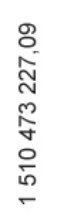 & 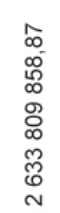 & 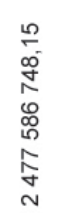 & $\begin{array}{l}\frac{0}{6} \\
i \\
0 \\
0 \\
\tilde{N} \\
\infty \\
m\end{array}$ & 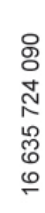 \\
\hline & 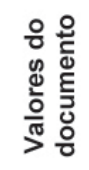 & के & $\bar{\omega}$ & $\bar{\omega}$ & ஸे & $\overline{\bar{\nu}}$ & के & $\begin{array}{l}\circ \\
\circ \\
\circ \\
\circ \\
\stackrel{\circ}{+}\end{array}$ & 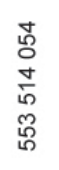 & $\begin{array}{l}\text { Oे } \\
\text { ठ̀ } \\
\text { ปे }\end{array}$ & 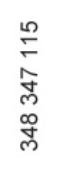 & 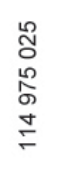 & 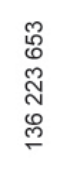 & 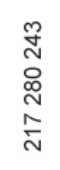 & 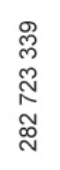 & 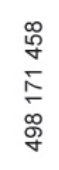 & 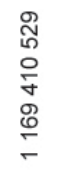 & $\begin{array}{l}\stackrel{0}{\circ} \\
\text { Ǹ } \\
\stackrel{-}{\circ} \\
\stackrel{-}{-}\end{array}$ & 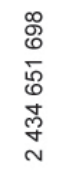 & $\begin{array}{l}\mathfrak{Y} \\
o \\
0 \\
0 \\
\hat{~} \\
\sim\end{array}$ & 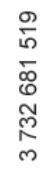 & \\
\hline \multicolumn{2}{|c|}{ 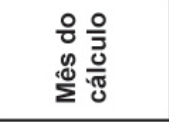 } & $\begin{array}{l}\stackrel{\infty}{\infty} \\
\stackrel{\infty}{\underline{\Xi}}\end{array}$ & 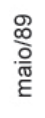 & $\begin{array}{l}\text { ㅇ } \\
\text { 유 }\end{array}$ & $\begin{array}{l}\bar{\Phi} \\
\text { 离 }\end{array}$ & $\begin{array}{l}\tilde{\sigma} \\
\text { 。े } \\
\tilde{\sigma}\end{array}$ & 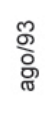 & $\begin{array}{l}\text { 志 } \\
\text { 总 }\end{array}$ & 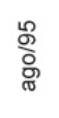 & இ & 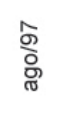 & $\begin{array}{l}\infty \\
\stackrel{\infty}{\grave{z}} \\
\stackrel{2}{c}\end{array}$ & @ & 올 & 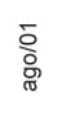 & ऽ్ & 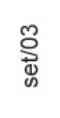 & 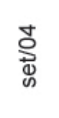 & 总 & ஜ & 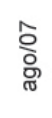 & \\
\hline \multicolumn{2}{|c|}{$\frac{8}{4}$} & 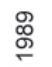 & 吕 & ळু & ๙ૂ & 兽 & 苂 & 怘 & 曽 & 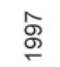 & $\stackrel{\infty}{\stackrel{\infty}{\circ}}$ & $\stackrel{\text { 号 }}{\circ}$ & ০ั & $\overline{\mathrm{N}}$ & ๙ั๊ & ఏ్రి & 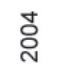 & ڤั & : & 今̀ & 。ั & 覀 \\
\hline
\end{tabular}

FONTES: Orçamento de Incentivos Fiscais (1989-1991); Orçamento da Renúncia da Receita Tributária (1992-1993); Demonstrativo de Benefícios Tributários (1994-2003); Demonstrativo de Gastos Governamentais Indiretos de Natureza Tributária (Gastos Tributários) (2004-2008). 
Para cada contribuição social, são apresentados os valores da renúncia tributária estimada, ano a ano, em valores da época; para facilitar a comparação, também são indicados os valores expressos, em reais, em agosto de 2007, mês no qual foi calculada a estimativa de renúncia para 2008 - último ano do período coberto pela pesquisa ${ }^{8}$.

O montante de renúncia tributária estimada para os 14 anos para os quais há cálculos disponíveis é de cerca de R\$ 95,8 bilhões, em valores de agosto de 2007. Esse valor é quase o dobro do total de recursos destinados pela lei do orçamento de 2007 (Lei n. 11 451, de 7.fev.2007) para o Ministério da Saúde (cerca de $\mathrm{R} \$ 49,7$ bilhões), e é quase 3,5 vezes maior do que o valor destinado ao Ministério da Educação (cerca de $\mathrm{R} \$ 27,6$ bilhões). O valor é mais do que o dobro do déficit do Regime Geral de Previdência Social em 2007 (cerca de R\$ 46 bilhões) (PREVIDÊNCIA FECHA..., 2008).

A Tabela 1 também mostra que, a partir de 2000, há um crescimento ininterrupto e vigoroso da estimativa de renúncia tributária da União, crescimento que se torna ainda mais expressivo de 2003 em diante, e que dispara entre 2007 e 2008.

Tudo isso pode ser dito mesmo sem levar em conta as numerosas omissões e lacunas dos demonstrativos de benefícios tributários publicados pelo Ministério da Fazenda. Em primeiro lugar, os demonstrativos simplesmente deixam de cobrir alguns anos da pesquisa. Por exemplo, os demonstrativos não estimam as renúncias causadas por benefícios referentes a quaisquer contribuições sociais para o período de seis anos que vai de 1989 até 1994 . No caso específico da CSLL, as estimativas de renúncia somente são calculadas a partir de 1997 . Já no caso da Cofins, as estimativas de renúncia remontam a 1995, mas não foram publicadas em 1997 e em 1999.

Em segundo lugar, há casos de benefícios vigentes que deixam de ser incorporados nas estimativas de renúncia. Tal negligência ocorre com benefícios referentes às três contribuições sociais, em todos os anos efetivamente cobertos pelos demonstrativos. Essa negligência agrava-se a partir do demonstrativo de 2003, com o aumento do número e da abrangência dos dispositivos que concedem benefícios tributários.

\footnotetext{
8 Os valores foram atualizados pelo Índice Nacional de Preços ao Consumidor - Amplo (IPC-A), do Instituto Brasileiro de Geografia e Estatística (IBGE). Para a atualização foi utilizado o programa disponível na página do Banco Central do Brasil na internet (cf. BANCO CENTRAL DO BRASIL, 2013). Para o cálculo, a data inicial sempre é o mês de elaboração do demonstrativo. A data final é agosto de 2007.
}

Em terceiro lugar, os demonstrativos omitem a renúncia gerada pelos benefícios concedidos aos exportadores ${ }^{9}$. Todavia, a Tabela 1 apontou que os dispositivos destinados às empresas exportadoras formam o segundo tipo mais freqüente de dispositivos que beneficiam empreendedores.

Por todo o exposto, está claro que é altíssimo o montante de receitas renunciadas por causa dos benefícios tributários relativos às contribuições sociais. Está claro também que, se as lacunas e omissões dos demonstrativos fossem sanadas, a estimativa da renúncia tributária da União, referente às contribuições sociais, seria ainda muito maior. A dimensão dos recursos públicos envolvidos justifica plenamente o estudo da matéria.

O estudo da concessão de benefícios tributários também se justifica à luz da literatura de ciência política. Theodore Lowi (1964) lançou a idéia - adotada e desenvolvida posteriormente por autores como Wilson e DiIulio Jr. (1980) - de que a policy (ou seja, a política pública) determina a politics (ou seja, a variedade de interesses afetados, o nível de mobilização desses interesses, o grau e a intensidade do conflito entre eles etc.). Lowi propôs uma tipologia de políticas públicas composta por três categorias: políticas distributivas, regulatórias e redistributivas. As políticas distributivas são "caracterizadas pela facilidade com que podem ser desagregadas e dispensadas em pequenas unidades, cada unidade mais ou menos em isolamento das outras unidades e de qualquer regra geral" (LOWI, 1964, p. 690). Por serem facilmente divisíveis, diversos interesses podem ser satisfeitos ao mesmo tempo. Assim, as políticas distributivas tendem a não gerar muito conflito entre os interesses envolvidos, pois seus benefícios concentram-se em ganhadores facilmente identificáveis, ao passo que seus custos são pulverizados entre diversos perdedores - isto é, todos aqueles que, em última instância, financiarão a distribuição dos favores particulares e clientelistas. Por essa razão, Lowi caracteriza as políticas distributivas como as políticas em que os interesses organizados agem "cada um por si" e segundo a lógica da "não interferência mútua".

A segunda categoria da tipologia de Lowi é formada pelas políticas regulatórias que, diferentemente das políticas distributivas, estabelecem regras de aplicação geral (por exemplo: regras gerais de abertura comercial ou de protecionismo). As políticas regulatórias deflagram conflito setorial intenso, colocando de um lado os setores potencialmente favorecidos (por

\footnotetext{
9 Com as exceções dos demonstrativos de 1995 e 1996.
} 
exemplo: em caso de abertura comercial, os setores econômicos mais competitivos) e, de outro lado, os setores potencialmente prejudicados (no caso de abertura comercial, os setores econômicos mais atrasados). Em outras palavras, a política regulatória identifica com mais clareza tanto os ganhadores quanto os perdedores.

Por fim, as políticas redistributivas determinam a alocação da riqueza, da propriedade e da renda em determinada sociedade. O conflito de interesses em torno das políticas redistributivas tende a ser muito intenso. Todavia, diferentemente do que ocorre com as políticas regulatórias, o impacto das políticas redistributivas é mais geral e menos setorial. As políticas redistributivas claramente colocam, de um lado, "os que têm", ou seja, "os provedores de dinheiro" (money providers); e, de outro lado, "os que não têm”, ou seja, os "demandantes de serviços" (service demanders).

Entendemos que a concessão de benefícios tributários ao empresariado pode ser caracterizada como uma política distributiva. De fato, as leis que concedem vantagens tributárias a segmentos empresariais específicos distribuem benefícios exclusivos para seus destinatários (e, eventualmente, para o conjunto de "insiders" que também inclui os fornecedores, os empregados e os consumidores dos empresários beneficiados). Tais leis também dispersam os custos dos privilégios tributários entre os "outsiders", isto é, todo o restante da sociedade, cuja carga tributária pode ser elevada para compensar a perda de receitas, ou que pode deixar de receber serviços públicos que seriam financiados pela receita das contribuições sociais renunciadas ${ }^{10}$.

Políticas distributivas como a concessão de benefícios tributários tendem a ser antecedidas por mobilização intensa dos beneficiários, que fazem forte lobby pontual pela aprovação das medidas desejadas, e tendem a provocar mobilização muito menor (se houver alguma) do restante da sociedade em sentido oposto (DEVER JR., 2008), em função da dificuldade de mobilização de grupos numerosos e dispersos (OLSON, 1999). Esse jogo enviesado em favor de interesses especiais pode levar a um resultado contrário ao interesse público (TULLOCK, 1989; 1993).
Compartilhamos da idéia de que o resultado contrário ao interesse público seja possível, mas não entendemos que esse resultado seja inevitável ${ }^{11}$. Admitimos, por exemplo, que desonerações fiscais para diversos segmentos produtivos - automóveis e construção, dentre outros - compuseram o pacote de políticas anticíclicas que foram implementadas com êxito pelo governo federal brasileiro para enfrentar e mitigar os efeitos internos da crise internacional de 2008 (juntamente com outras medidas tais como a manutenção do gasto público, com o Programa de Aceleração do Crescimento (PAC) e a expansão do crédito ao setor produtivo, por meio de bancos estatais como o BNDES e o Banco do Brasil) (PINTO, CARDOSO JR. \& LINHARES, 2010, p. 25). Portanto, este trabalho não advoga a revogação dos benefícios tributários para o empresariado. Diferentemente disso, entendemos que os riscos colocados pela política de concessão de benefícios tributários precisam ser enfrentados por meio de arquitetura institucional adequada. A renúncia tributária é um instrumento que, se for bem utilizado, pode trazer vantagens para seus beneficiários, sem prejudicar o restante da sociedade - e, em vez disso, beneficiando-o também. Todavia, a emergência do potencial positivo dos benefícios tributários tende a ser favorecida quando esses benefícios são adotados de modo transparente e fundamentados em evidências fortes de eficiência, eficácia e efetividade. Justamente por isso, voltamos nossa atenção para a presença ou a ausência de preocupação com esses elementos nas leis que instituíram benefícios tributários, no período considerado.

O presente artigo contém outras quatro seções, além dessa seção inicial, que procura justificar empiricamente e teoricamente o estudo da questão dos benefícios tributários. A seção seguinte identifica a origem e a espécie das proposições legislativas que instituíram benefícios tributários para o empresariado do país, no período analisado. A terceira seção focaliza a exposição de motivos dessas proposições legislativas, para mensurar o grau de preocupação de seus formuladores e proponentes com a eficiência, eficácia e efetividade dos benefícios tributários. A quarta seção analisa o conteúdo dos dispositivos legais efetivamente aprovados, para verificar $(i)$ se estabelecem prazos de vigência para os benefícios concedidos, (ii)

\footnotetext{
11 Nesse sentido, distanciamo-nos da visão liberal extremista, que repele o estado ativo e defende o estado mínimo por causa do risco de rent seeking. Cohen e Rogers (1992) submetem tal visão, que denominam de "constitucionalismo neoliberal", a uma excelente análise crítica.
} 
condicionantes para a concessão desses benefícios e (iii) mecanismos de monitoramento, controle e avaliação da eficiência, eficácia e efetividade dos benefícios. A última seção do artigo apresenta as considerações finais.

\section{ORIGEM E ESPÉCIE DAS PROPOSIÇÕES LEGISLATIVAS QUE CONCEDEM BENEFÍCIOS TRIBUTÁRIOS AO EMPRESARIADO}

Passemos, então, à análise da formulação das leis que concederam benefícios, para avaliar se nesse estágio do ciclo das políticas públicas estiveram presentes medidas que assegurem a transparência, a eficiência, a eficácia e a efetividade dos benefícios concedidos.

A Tabela 2 mostra a origem das proposições legislativas que resultaram em benefícios fiscais referentes ao PIS, à Cofins e à CSLL, desde a promulgação da atual constituição até 01/01/2009. Conforme a Tabela 2, a grande maioria dessas proposições (48 proposições, ou seja, cerca de $92 \%$ do total) é de autoria do poder executivo.

TABELA 2 - ORIGEM DOS DISPOSITIVOS QUE INSTITUÍRAM BENEFÍCIOS FISCAIS REFERENTES AO PIS, À COFINS E À CSLL (5.OUT.1988-1.JAN.2009)

\begin{tabular}{|l|c|c|}
\hline & Número de Dispositivos & $\%$ \\
\hline Poder Executivo & 48 & 92,3 \\
Poder Legislativo & 4 & 7,7 \\
Total & 52 & 100 \\
\hline
\end{tabular}

FONTE: Brasil, Câmara dos Deputados (2013) e Brasil, Senado Federal (2013)

A Tabela 3, por sua vez, foca especificamente as
48 proposições legislativas de autoria do poder Executivo e indica o tipo de proposição adotado por aquele poder para instituir benefícios tributários referentes às contribuições sociais. A tabela mostra que em apenas um caso o governo utilizou o projeto de lei complementar. Em nove casos (18,8\% do total), o poder Executivo preferiu projetos de lei ordinária. $\mathrm{Na}$ grande maioria dos casos (38 em 48, ou seja, 79,2\%), o Executivo instituiu os benefícios por meio de Medidas Provisórias (MPs) - atos de prerrogativa exclusiva desse poder, que possuem aplicação instantânea desde sua edição, produzindo, portanto, efeitos imediatos.

TABELA 3 - TIPO DE PROPOSIÇÃO ADOTADO PELO PODER EXECUTIVO

\begin{tabular}{|lcc|}
\hline & $\begin{array}{c}\text { Número de } \\
\text { Dispositivos }\end{array}$ & $\%$ \\
\hline Medidas Provisórias & 38 & 79,2 \\
Projetos de Lei Ordinária & 9 & 18,8 \\
Projetos de Lei Complementar & 1 & 2 \\
Total & 48 & 100 \\
\hline
\end{tabular}

FONTE: Brasil, Câmara dos Deputados (2013) e Brasil, Senado Federal (2013)

A Tabela 4 mostra que a tendência de o poder Executivo instituir benefícios tributários unilateralmente, por meio de MPs, remonta ao governo Franco, com a edição da MP n. 335, de 27 de julho de 1993. Essa tendência fortaleceu-se sob os dois governos de Fernando Henrique Cardoso, quando 16 dispositivos foram gerados por MP $(80 \%$ dos 20 criados), e foi não apenas mantida, como também bastante reforçada, sob o governo Lula, quando 21 dispositivos foram gerados por meio de MPs $(91,3 \%$ dos 23 que criou).

TABELA 4 - TIPO DE PROPOSIÇÃO ADOTADO PELO PODER EXECUTIVO, POR GOVERNO

\begin{tabular}{|l|c|c|c|c|}
\hline & $\begin{array}{c}\text { Medidas } \\
\text { Provisórias }\end{array}$ & $\begin{array}{c}\text { Projetos de Lei } \\
\text { Ordinária }\end{array}$ & $\begin{array}{c}\text { Projetos de Lei } \\
\text { Complementar }\end{array}$ & Total \\
\hline Sarney & 0 & $1(100 \%)$ & 0 & $1(100 \%)$ \\
Collor & 0 & $2(66,6 \%)$ & $1(33,3 \%)$ & $3(100 \%)$ \\
Franco & $1(100)$ & 0 & 0 & $1(100 \%)$ \\
FHC I e II & $16(80)$ & $4(20 \%)$ & 0 & $20(100 \%)$ \\
Lula I e II & $21(91,3)$ & $2(8,7 \%)$ & 0 & $23(100 \%)$ \\
Total & $38(79,2)$ & $9(18,8 \%)$ & $1(2 \%)$ & $48(100 \%)$ \\
\hline
\end{tabular}

FONTE: Brasil, Câmara dos Deputados (2013) e Brasil, Senado Federal (2013)

NOTA: 1. Governo considerado até o dia 31 de dezembro de 2008. 
Retomando o que discutimos na seção anterior, a política de benefícios tributários pode ser classificada, nos termos de Lowi (1964), como uma política distributiva, com benefícios concentrados e custos difusos, e que, por causa dessa característica, usualmente estimula a mobilização favorável dos grupos de interesse beneficiados, e nem sempre estimula a mobilização fiscalizadora do restante da sociedade, que paga a conta. Desse modo, a escolha de MPs como instrumento para a instituição dos benefícios tributários dá margem à discricionariedade do alto escalão da burocracia federal e favorece a influência pouco transparente dos interesses contemplados, além de nem sempre favorecer o debate e a negociação de propostas com a oposição e a sociedade civil.

Nessa altura do trabalho é importante chamar a atenção para duas coisas. Em primeiro lugar, é importante destacar que não há nenhuma garantia de que, caso o poder Executivo resolvesse propor todos os benefícios por meio de projetos de lei, o Congresso Nacional viria a levantar questões a respeito da eficiência, eficácia e efetividade dos benefícios propostos. Mas a escolha desses tipos de proposição legislativa proporcionaria pelo menos uma oportunidade para que tais preocupações fossem levadas em conta, antes que os benefícios viessem a vigorar.

Em segundo lugar, é relevante enfatizar que, embora as MPs tenham efeito imediato, elas só passam a valer definitivamente depois de transformadas em normas jurídicas, ou seja, depois que o Congresso Nacional pronuncia-se sobre elas, podendo aprová-las, alterálas ou rejeitá-las ${ }^{12}$. Como vemos na Tabela 5, o Congresso Nacional não assumiu um papel totalmente passivo em relação às MPs que instituíram benefícios tributários referentes ao PIS, à Cofins e à CSLL, alterando 44,7\% das MPs que posteriormente aprovou (17 de 38 MPs).

\footnotetext{
12 Em 11 de setembro de 2001, a Emenda Constitucional n. 32 alterou o rito de apreciação das MPs. Antes dessa Emenda, era permitida a contínua reedição das MPs vigentes. A referida Emenda estabeleceu que: ( $i$ ) as MPs perderão eficácia, desde a edição, se não forem convertidas em lei no prazo de 60 dias, prorrogável uma vez por igual período, devendo o Congresso Nacional disciplinar, por decreto legislativo, as relações jurídicas delas decorrentes; (ii) se a MP não for apreciada em até 45 dias contados de sua publicação, entrará em regime de urgência, subseqüentemente, em cada uma das Casas do Congresso Nacional, ficando sobrestadas, até que se ultime a votação, todas as demais deliberações legislativas da Casa em que estiver tramitando; (iii) prorrogar-se-á uma única vez, por igual período, a vigência de MP que, no prazo de 60 dias, contado de sua publicação, não tiver a sua votação encerrada nas duas Casas do Congresso Nacional.
}

TABELA 5 - MEDIDAS PROVISÓRIAS QUE FORAM ALTERADAS PELO CONGRESSO NACIONAL

\begin{tabular}{|l|c|c|}
\hline & Número de MPs & $\%$ \\
\hline Alteradas CN & 17 & 44,7 \\
Não alteradas & 21 & 55,3 \\
Total & 38 & 100 \\
\hline
\end{tabular}

FONTE: Brasil, Câmara dos Deputados (2013) e Brasil, Senado Federal (2013)

Embora o Congresso Nacional não tenha se mostrado totalmente passivo, a questão é que essa intervenção se dá necessariamente a posteriori, quando os efeitos da MP já estão plenamente vigentes, criando um custo para a alteração do novo status quo com a alteração ou, sobretudo, com a rejeição da MP. Em outras palavras, mesmo nos casos em que o Congresso Nacional interveio alterando as MPs, a escolha desse tipo de proposição legislativa não garantiu a existência de discussões públicas prévias em que preocupações com transparência, eficiência, eficácia e efetividade pudessem pelo menos ter sido aventadas.

\section{A EXPOSIÇÃO DE MOTIVOS DAS PROPO- SIÇÕES LEGISLATIVAS QUE CONCEDEM BENEFÍCIOS TRIBUTÁRIOS}

Até aqui nossa discussão girou em torno da origem e das espécies das proposições legislativas que instituíram benefícios tributários relativos às contribuições sociais. Daqui em diante nossa discussão girará em torno do conteúdo da exposição de motivos dessas proposições legislativas. De fato, as próximas tabelas de nosso artigo têm como objeto a exposição de motivos apresentada pelos autores de cada uma das proposições que originaram leis que instituem benefícios tributários. A exposição de motivos é a justificativa do autor de uma proposição legislativa para sua apresentação ao Congresso Nacional. Nossa ideia é verificar, por meio da análise das exposições de motivos, se a preocupação com a eficiência, a eficácia e a efetividade dos benefícios tributários esteve presente, de alguma forma, no horizonte de pensamento de seus proponentes, no momento em que as proposições legislativas estavam sendo formuladas e apresentadas.

Todas as exposições de motivos apresentam algum objetivo ou resultado a ser alcançado. Contudo, a grande maioria das exposições de motivos restringe-se a afirmar, de maneira genérica, que os benefícios propostos "favoreceriam o crescimento econômico", "favoreceriam as exportações", "reduziriam a carga tributária" etc., sem especificar de fato a mudança do status quo que se deseja. A Tabela 6 , a seguir, mostra 
que, de todas as proposições legislativas que deram origem aos benefícios tributários estudados, apenas uma continha, em sua exposição de motivos, alguma menção explícita a resultados ou objetivos mensuráveis a serem alcançados pela aprovação do dispositivo legal. A apresentação de resultados ou objetivos mensuráveis na justificativa de um projeto é uma medida que denota preocupação do proponente com a eficácia e a efetividade do benefício proposto no momento da formulação da política. A proposição cuja justificativa mencionou objetivos mensuráveis foi a MP n. 252/ 2005, de autoria do governo Lula, que deu origem à Lei n. 11 196/2005, conhecida como a "Lei do Bem". Um dos benefícios tributários estabelecidos pela MP n. 252/05 estava vinculado à instituição do Regime Especial de Tributação para Plataforma de Exportação de Serviços de Tecnologia da Informação (Repes). A exposição de motivos dessa MP mencionou que o REPES visava "contribuir para o atingimento da meta da política industrial, tecnológica e de comércio exterior de elevar as exportações de software e serviços de TI de US\$ 100 milhões por ano, em 2001, para US\$ 2 bilhões por ano, em 2007".

TABELA 6 - PROPOSIÇÕES LEGISLATIVAS CUJAS EXPOSIÇÕES DE MOTIVOS MENCIONAM RESULTADOS OU OBJETIVOS MENSURÁVEIS

\begin{tabular}{|l|c|c|}
\hline & Número de Projetos & $\%$ \\
\hline Com objetivos & 1 & 2 \\
Sem objetivos & 50 & 98 \\
Total & $51^{1}$ & 100 \\
\hline
\end{tabular}

FONTE: Brasil, Câmara dos Deputados (2013) e Brasil, Senado Federal (2013)

NOTA: 1. Não foi possível encontrar a exposição de motivos da MP n. 1729/88 que deu origem à lei ordinária n. 9732 em 11 de dezembro de 1998.

A previsão de renúncia de receita na exposição de motivos da proposição legislativa que institui benefício tributário é outra medida que denota preocupação do formulador com a qualidade do benefício proposto. A Tabela 7, a seguir, aponta que, de todas as proposições legislativas consideradas nesse trabalho, apenas 11 ( $21,6 \%$ do total) continham estimativas de renúncia de receita em suas justificativas, referentes às contribuições sociais. Por um lado, é importante mencionar que essas 11 proposições foram apresentadas depois da aprovação da Lei Complementar n. 101, de 2005, Lei de Responsabilidade Fiscal (LRF), que estabelece o seguinte em seu artigo 14: “Art. 14. A concessão ou ampliação de incentivo ou benefício de natureza tributária da qual decorra renúncia de receita deverá estar acompanhada de estimativa do impacto orçamentário-financeiro no exercício em que deva iniciar sua vigência e nos dois seguintes, atender ao disposto na lei de diretrizes orçamentárias e a pelo menos uma das seguintes condições:

I - Demonstração pelo proponente de que a renúncia foi considerada na estimativa de receita da lei orçamentária, na forma do art. 12, e de que não afetará as metas de resultados fiscais previstas no anexo próprio da lei de diretrizes orçamentárias;

II - Estar acompanhada de medidas de compensação, no período mencionado no caput, por meio do aumento de receita, proveniente da elevaçãode alíquotas, ampliação da base de cálculo, majoração ou criação de tributo ou contribuição" (sem grifo no original).

A LRF parece, portanto, ter aumentado a preocupação dos formuladores com relação aos custos das renúncias tributárias, obrigando-os a preverem medidas de compensação ou o enquadramento da renúncia ao orçamento previsto. Por outro lado, conforme a Tabela 7, cumpre destacar que, mesmo sob a vigência da LRF, a grande maioria das proposições legislativas $(66,7 \%$ dos casos) continuou não apresentando previsões de renúncia tributária em suas justificativas.

TABELA 7 - PROPOSIÇÕES LEGISLATIVAS ANTERIORES E POSTERIORES À LRF, CUJAS "EXPOSIÇÕES DE MOTIVOS" CONTÊM PREVISÕES DE RENÚNCIADE RECEITA

\begin{tabular}{|l|c|c|c|}
\hline & $\begin{array}{c}\text { Com } \\
\text { estimativas }\end{array}$ & $\begin{array}{c}\text { Sem } \\
\text { estimativas }\end{array}$ & Total \\
\hline Antes da LRF & 0 & $18(100 \%)$ & 18 \\
Após a LRF & $11(33,3 \%)$ & $22(66,7 \%)$ & 33 \\
Total & $11(21,6 \%)$ & $40(78,4 \%)$ & $51^{1}$ \\
\hline
\end{tabular}

FONTE: Brasil, Câmara dos Deputados (2013) e Brasil, Senado Federal (2013)

NOTA: 1. Não foi possível encontrar a exposição de motivos da MP n. 1 729/88 que deu origem à Lei Ordinária n. 9 732, em 11 de dezembro de 1998.

Um terceiro indicativo da preocupação do formulador com a qualidade da política que propõe é a menção, na justificativa da proposta, a mecanismos de controle de eficiência, que assegurem a comparação frequente de custos e benefícios, permitindo assim concluir se a política sugerida realmente "compensa". 
A Tabela 8 mostra que, de todas as proposições legislativas que originaram os benefícios estudados, somente uma mencionava, em sua exposição de motivos, mecanismos de controle de eficiência: tratase do PL n. 3 837/00, que resultou na Lei n. 10 147/ 00, que reduziu a carga tributária de produtores, importadores e comerciantes de medicamentos. Entre outras razões, a justificativa desse PL defendia sua aprovação por obrigar o poder Executivo federal de publicar relatórios semestrais identificando, de um lado, o montante de receitas fiscais renunciadas e, de outro lado, o efeito dos benefícios concedidos sobre o preço dos medicamentos aos consumidores.

TABELA 8 - PROPOSIÇÕES LEGISLATIVAS CUJAS "EXPOSIÇÕES DE MOTIVOS" MENCIONAM MECANISMOS DEAVALIAÇÃO

\begin{tabular}{|lcc|}
\hline & Número de Projetos & $\%$ \\
\hline Com avaliação & 1 & 2 \\
Sem avaliação & 50 & 98 \\
Total & $51^{1}$ & 100 \\
\hline
\end{tabular}

FONTE: Brasil, Câmara dos Deputados (2013) e Brasil, Senado Federal (2013).

NOTA: 1. Não foi possível encontrar a exposição de motivos da MP n. $1729 / 88$ que deu origem à Lei Ordinária n. 9 732, em 11 de dezembro de 1998.

\section{O TEXTO DOS DISPOSITIVOS LEGAIS QUE CONCEDEM BENEFÍCIOS TRIBUTÁRIOS}

A partir daqui analisamos o texto dos dispositivos legais efetivamente aprovados entre 5 de outubro de 1988 e $1^{\circ}$ de janeiro de 2009. Enquanto na seção anterior nosso objetivo era verificar se os proponentes dos projetos preocupavam-se com mecanismos que auferissem a eficiência, a eficácia e a efetividade das propostas, interessa-nos agora averiguar se os textos finais das 50 leis e das duas medidas provisórias vigentes desde 2001 apresentam tais ferramentas.

A Tabela 9 mostra que apenas $23 \%$ dos dispositivos legais (12 de 52 dispositivos) estipulam prazo final para algum dos benefícios concedidos. Isso indica, portanto, que os benefícios instituídos pela grande maioria dos dispositivos legais (40 de 52, ou seja, 77\%) não têm data para acabar, podendo vigorar indefinidamente. Poderia ser útil o estabelecimento de prazos de vigência para os benefícios concedidos, ao término dos quais o benefício poderia ser mantido, alterado ou extinto, dependendo da avaliação de sua eficiência, eficácia e efetividade.

TABELA 9-DISPOSITIVOS LEGAIS QUE ESTABELECEM PRAZO DE VIGÊNCIA PARA OS BENEFÍCIOS CONCEDIDOS

\begin{tabular}{|lcc|}
\hline & $\begin{array}{c}\text { Número de Leis ou } \\
\text { Medidas Provisórias }\end{array}$ & $\%$ \\
\hline $\begin{array}{l}\text { Com prazo final } \\
\text { estabelecido }\end{array}$ & 12 & 23 \\
$\begin{array}{l}\text { Sem prazo final } \\
\text { estabelecido } \\
\text { Total }\end{array}$ & 40 & 77 \\
\hline
\end{tabular}

FONTE: Brasil, Câmara dos Deputados (2013) e Brasil, Senado Federal (2013)

Apesar de apenas 23\% dos dispositivos legais estabelecerem prazos pré-determinados de vigência para os benefícios, a Tabela 10 mostra uma tendência recente de aumento no uso desse artifício. A tendência remonta ao governo Franco, quando a única lei aprovada que concedia benefícios tributários referentes às contribuições sociais (Lei n. 8 696/93) valeu-se do mecanismo. Desde então, verifica-se uma tendência crescente que atingiu $12,5 \%$ dos dispositivos legais sob os governos de Cardoso, e 34,8\% dos dispositivos legais aprovados desde o início do governo Lula até o final da primeira metade de seu segundo mandato.

TABELA 10 - DISPOSITIVOS LEGAIS QUE APRESENTAM PRAZO DE VIGÊNCIAEM SEU TEXTO, POR GOVERNO

\begin{tabular}{|l|c|c|c|}
\hline & Com prazo final estabelecido & Sem prazo final estabelecido & Total \\
\hline Sarney & 0 & $1(100 \%)$ & 1 \\
Collor & 0 & $3(100 \%)$ & 3 \\
Franco & $1(100 \%)$ & 0 & 1 \\
FHC I e II & $3(12,5 \%)$ & $21(87,5 \%)$ & 24 \\
Lula I e II & $8(34,8 \%)$ & $15(65,2 \%)$ & 23 \\
Total & $12(23 \%)$ & $40(77 \%)$ & 52 \\
\hline
\end{tabular}

FONTE: Brasil, Câmara dos Deputados (2013) e Brasil, Senado Federal (2013).

NOTA: 1. Governo considerado até o dia 31 de dezembro de 2008. 
Outro mecanismo que pode contribuir para a qualidade da política de benefício tributário é o tipo de condição que o governo estabelece para a concessão do benefício. Nesse ponto, estamos interessados em averiguar se há mecanismos por meio dos quais o poder Executivo pode excluir ou incluir beneficiados após a avaliação de informações, projetos e propostas por eles encaminhadas.

Nesse trabalho, focaremos dois tipos de condicionantes possíveis: controle a priori e controle a posteriori. O primeiro é um mecanismo pelo qual os potenciais beneficiados submetem, ao poder Executivo, projetos ou propostas que, após avaliação e aprovação, dão-lhes direito ao benefício. Esse tipo de instrumento é freqüentemente utilizado para a concessão de benefícios relacionados à Zona Franca de Manaus (ZFM), cujos beneficiados devem ter seus projetos aprovados pela Superintendência da Zona Franca de Manaus (Suframa). O segundo tipo de controle, por sua vez, refere-se ao estabelecimento de prestação de contas aos órgãos executivos por parte do beneficiado. O exemplo típico desse segundo tipo de controle são os benefícios concedidos pela Lei do Bem (Lei n. 11 196/05) a empresas que investem em Ciência, Tecnologia e Inovação. As empresas beneficiadas por essa lei devem submeter anualmente informações ao Ministério da Ciência e Tecnologia, que as avalia de modo a garantir que as contrapartidas necessárias estão sendo cumpridas de acordo com os objetivos da política.

A Tabela 11 mostra que somente 12 dispositivos legais, ou $23 \%$ do total de dispositivos analisados, possuem algum tipo de condicionante que garante o direito ao benefício. Desses, oito $(66,7 \%)$ apresentam mecanismos de controle a priori e quatro $(33,3 \%)$ apresentam algum tipo de controle a posteriori (Tabela 12).

TABELA 11 - DISPOSITIVOS LEGAIS QUEAPRESENTAM CONDICIONANTES DEAPROVAÇÃO

\begin{tabular}{|l|c|c|}
\hline & $\begin{array}{c}\text { Número de } \\
\text { Dispositivos }\end{array}$ & $\%$ \\
\hline Com condicionantes & 12 & 23 \\
Sem condicionantes & 40 & 77 \\
Total & 52 & 100 \\
\hline
\end{tabular}

FONTE: Brasil, Câmara dos Deputados (2013) e Brasil, Senado Federal (2013).
TABELA 12 - DISPOSITIVOS LEGAIS POR TIPO DE CONDICIONANTE DEAPROVAÇÃO

\begin{tabular}{|l|c|c|}
\hline & $\begin{array}{c}\text { Número de } \\
\text { Dispositivos }\end{array}$ & $\%$ \\
\hline Controle a priori & 8 & $66,7 \%$ \\
Controle a posteriori & 4 & $33,3 \%$ \\
Total & 12 & $100 \%$ \\
\hline
\end{tabular}

FONTE: Brasil, Câmara dos Deputados (2013) e Brasil, Senado Federal (2013).

Por fim, verificamos se os formuladores das políticas de benefícios tributários estabeleceram mecanismos de prestação de contas à sociedade, que pudessem basear uma avaliação em termos de eficiência, eficácia e efetividade ${ }^{13}$. Como vemos na Tabela 13, somente dois dispositivos (3,9\% do total) apresentam esse tipo de controle: (i) a Lei n. 10 147/00, oriunda do PL n. 3 837/00, cuja justificação já previa e seu artigo $6^{\circ}$ estabeleceu que "[...] o Poder Executivo encaminhará, semestralmente, ao Congresso Nacional o resultado da implementação desta Lei [...]" e (ii) a Lei n. 11 096/05, fruto da MP n. 213/04, que instituiu o Programa Universidade para Todos (Prouni) e estabeleceu em seu artigo 18 que "o Poder Executivo dará, anualmente, ampla publicidade dos resultados do Programa".

TABELA 13 - DISPOSITIVOS LEGAIS QUE ANTEVEJAM MECANISMOS DEAVALIAÇÃO

\begin{tabular}{|l|c|c|}
\hline & $\begin{array}{c}\text { Número de } \\
\text { Dispositivos }\end{array}$ & $\%$ \\
\hline Com avaliação & 2 & $3,9 \%$ \\
Sem avaliação & 50 & $96,1 \%$ \\
Total & 52 & $100 \%$ \\
\hline
\end{tabular}

FONTE: Brasil, Câmara dos Deputados (2013) e Brasil, Senado Federal (2013).

\footnotetext{
13 Convém ressaltar que estamos restringindo-nos ao texto da lei para focar o momento da formulação da política pública. Há casos em que o órgão gestor produz relatórios de avaliação sobre os benefícios sem prévia obrigação legal como, por exemplo, o Relatório Anual de Utilização dos Incentivos Fiscais produzido anualmente pelo Ministério da Ciência e Tecnologia para divulgar os números e beneficiários referentes aos benefícios concedidos às empresas que investem em Ciência, Tecnologia e Inovação (Lei do Bem n. 11 196/05).
} 


\section{CONCLUSÕES}

Ao fim deste trabalho, a principal conclusão a que chegamos é que, no estágio de formulação dos dispositivos legais que instituíram benefícios tributários referentes às contribuições sociais, pouquíssima atenção foi dada à criação de medidas que assegurem a transparência, eficiência, eficácia e efetividade dos benefícios concedidos - valores fundamentais a serem considerados em boas políticas públicas. Tal constatação é preocupante, pois é crescente o número de dispositivos legais que instituem esse tipo de benefícios, e é gigantesco o volume de renúncias realizadas.

O poder Executivo foi a origem da grande maioria dos dispositivos legais que concedem benefícios tributários ao empresariado, e a Medida Provisória foi a espécie de proposição legislativa escolhida pelo poder Executivo para instituir a grande maioria dos benefícios. As MPs são proposições legislativas de aplicação instantânea, que produzem efeitos imediatos. Elas podem resultar de negociação do governo com os setores regulados (MANCUSO, 2003), mas dão grande margem à discricionariedade do alto escalão da burocracia federal que as formula. A opção por MPs para a instituição de benefícios tributários nem sempre favorece a transparência e o diálogo com a sociedade, representada no Congresso Nacional. Em decorrência da aplicação instantânea das MPs, o Congresso Nacional é privado da oportunidade de levantar questões referentes à transparência, eficiência, eficácia e efetividade dos benefícios propostos, antes que os mesmos passem a vigorar.

Quanto à exposição de motivos das proposições legislativas que instituem benefícios tributários, seria interessante que ela apresentasse estimativas da receita a renunciar e indicasse objetivos e resultados mensuráveis a serem alcançados - mas raramente isso ocorre. É importante que se aponte o status quo do qual se parte e o que se deseja estabelecer com uma política. Somente com esta informação é possível, $a$ posteriori, auferir o resultado dos gastos tributários empreendidos.

Por fim, os dispositivos legais efetivamente aprovados raramente estabelecem prazos de vigência para os benefícios tributários concedidos, ou condicionantes para fazer jus a eles. Mais rara ainda é a previsão de mecanismos de avaliação constante da eficiência, eficácia e efetividade dos benefícios concedidos - por exemplo, pelo Ministério da Fazenda, pelos ministérios setoriais ou pelo Tribunal de Contas da União. A redação final das leis que concedem benefícios tributários poderia contemplar esses elementos, além de determinar os órgãos responsáveis pela avaliação dos resultados alcançados. Como mencionado na seção introdutória deste artigo, a avaliação da eficiência, eficácia e efetividade dos benefícios tributários é um instrumento importante para contornar os perigos que cercam a política, e não deveria depender exclusivamente de iniciativas autônomas e unilaterais de algumas burocracias públicas envolvidas na gestão dos benefícios.

Wagner Pralon Mancuso (pralon@usp.br) é Doutor em Ciência Política pela Universidade de São Paulo (USP) e professor do Programa de Pós-Graduação em Ciência Política da mesma universidade.

Davi Cordeiro Moreira (davi.moreira@gmail.com) é Doutorando em Ciência Política pela Universidade de São Paulo (USP).

\section{REFERÊNCIAS BIBLIOGRÁFICAS}

COHEN, J. \& ROGERS, J. 1992. Secondary Associations and Democratic Governance. Politics \& Society, Washington (DC), v. 20, n. 4, p. 293472, Dec. Disponível em: http://cows.org/joel/pdf/ a_057.pdf. Acesso em: 26.abr.2013.

DEVER JR., P. 2008. Reforming Subsidies in the Federal Budget. Politics \& Policy, Washington (DC), v. 36 , n. 5 , p. $854-878$, Oct.

GRAETZ, M. J. 2007. Tax Reform Unraveling. The Journal of Economic Perspectives, Pittsburgh, v. 21, n. 1, p. 69-90, Winter.

LOWI, T. 1964. American Business, Public Policy Case-Studies, and Political Theory. World Politics,
Baltimore, v. 16, n. 4, p. 677-715, July.

MANCUSO, W. P. 2003. Construindo leis: os construtores e as concessões de serviços. Lua Nova, São Paulo, n. 58, p. 61-87. Disponível em: http:// www.scielo.br/pdf/ln/n58/a05n58.pdf. Acesso em: 29.abr.2013.

MANCUSO, W. P.; GONÇALVES, M. P. \& MENCARINI, F. 2010. Colcha de retalhos: a política de concessão de benefícios tributários ao empresariado no Brasil (1988-2006). In: MANCUSO, W. P.; LEOPOLDI, M. A. P. \& IGLECIAS, W. (orgs.). Estado, empresariado e desenvolvimento no Brasil: novas teorias, novas 
trajetórias. São Paulo: Cultura.

PINTO, E. C.; CARDOSO JR., J. C. \& LINHARES, P. T. 2010. O estado brasileiro e o desenvolvimento nacional. In: Estado, instituições e democracia: desenvolvimento. Brasília: IPEA.

OLSON, M. 1999. A lógica da ação coletiva. São Paulo: USP.

RIPLEY, R. B. 1995. Stages of the Policy Process. In: MCCOOL, D. C. (ed.). Public Policy Theories, Models, and Concepts: An anthology. New Jersey: Prentice Hall.

SECCHI, L. 2010. Políticas públicas: conceitos, esquemas de análise, casos práticos. São Paulo: Cengage Learning.

TULLOCK, G. 1989. The Economics of Special Privilege and Rent Seeking. Norwell: Kluwer. 1993. Rent Seeking. London: Edward Elgar.

WILSON, J. Q. \& DIIULIO JR., J. J. 1980. American Government: Institutions and Policies. Lexington: D. C. Heath and Company.

Outras fontes

BANCO CENTRAL DO BRASIL. 2013. Correção de valores. Índice de preços. Disponível em: https:/ /www3.bcb.gov.br/CALCIDADAO/publico/ exibirFormCorrecaoValores.do?method=exibir FormCorrecaoValores. Acesso em: 26.abr.2013.

BRASIL. 2013. Sítio da Subchefia para Assuntos Jurídicos da Casa Civil da Presidência da República, seção "Legislação". Disponível em: http:// www4.planalto.gov.br/legislacao. Acesso em: 25.abr.2013.

BRASIL. CÂMARA DOS DEPUTADOS. 2013. Diários da Câmara dos Deputados. Disponível em: http://imagem.camara.gov.br/diarios.asp. Acesso em: 26.abr.2013. Os Diários do Congresso Nacional estão disponíveis no mesmo local.

BRASIL. CÂMARA DOS DEPUTADOS. 2013. Disponível em: http://www2.camara.leg.br/atividadelegislativa/legislacao. Acesso em: 20.mai.2013

BRASIL. RECEITA FEDERAL. 2012. Contribuição para o PIS/Pasep e Cofins. Coletânea da Legislação. Disponível em: http://www.receita.fazenda. gov.br/publico/legislacao/coletanea/ coletaneapiscofins.pdf. Acesso em: 26.abr.2013.

BRASIL. SENADO FEDERAL. 2013. Diários do Senado Federal. Disponível em: http:// www6.senado.gov.br/diarios/Diario. Contém os diários do Congresso Nacional.

BRASIL. SENADO FEDERAL. 2013. Disponível em: http://www.senado.gov.br/legislacao/. Acesso em: 20.mai.2013

BRASIL. SENADO FEDERAL. 2013. Disponível em: http://www6.senado.gov.br/diarios/Diario. Acesso em 20.mai.2013

Previdência fecha 2007 com déficit de R \$ 46,004 bilhões. 2008. Folha de S. Paulo, 22.jan. Disponível em: http://www1.folha.uol.com.br/folha/dinheiro/ ult91u365895.shtml. Acesso em: 26.abr.2013. Os dados também podem ser encontrados na base de dados da Câmara dos Deputados: http:// bd.camara.gov.br/bd/ e do Senado Federal: http:// www6.senado.gov.br/diarios/Diario. Acesso em: 26.abr.2013. 